Climate Machines, Fascist Drives, and Truth 
This page intentionally left blank 


\section{Climate Machines}

Fascist Drives and Truth

WILLIAM E. CONNOLLY 
(c) 2019 Duke University Press

All rights reserved

Printed in the United States of America

on acid-free paper $\infty$

Designed by Matthew Tauch

Typeset in Whitman and Helvetica Neue LT Std

by Westchester Publishing Services

Library of Congress Cataloging-in-Publication Data

Names: Connolly, William E., [date] author.

Title: Climate machines, fascist drives, and truth /

William E. Connolly.

Description: Durham : Duke University Press, 2019. |

Includes bibliographical references and index.

Identifiers: LCCN 2019008725 (print)

LCCN 2019016269 (ebook)

ISBN 9781478007258 (ebook)

ISBN 9781478005896 (hardcover : alk. paper)

ISBN 9781478006558 (pbk. : alk. paper)

Subjects: LCSH: Global environmental change-Philosophy. |

Climatic changes-Philosophy. | Global environmental

change-Political aspects. | Capitalism-Philosophy. |

Truth-Philosophy.

Classification: LCC GE149 (ebook) | LCC GE149 .C665 2019

(print) | DDC 304.2/8-dc23

LC record available at https://lccn.loc.gov/2019008725 